\title{
Prevalence and risk factors of soil- transmitted helminthiasis among school children living in an agricultural area of North Sumatera, Indonesia
}

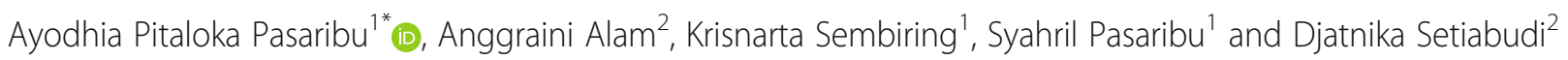

\begin{abstract}
Background: Soil-transmitted helminth infection (STH) is one of the neglected tropical disease that affects approximately 2 billion people globally. School children represent the age group that is most commonly infected with STHs, resulting in poor school performance, impaired cognitive function, and many other detrimental effects. The transmission of STH is determined by many factors, such as hygiene and sanitation. Understanding the factors that influence disease transmission in a particular area is key to effective STH control. The objective of this study was to determine the prevalence of STH in North Sumatera and to identify the associated risk factors among school children.
\end{abstract}

Methods: A cross-sectional study was carried out among primary school children in Suka village, Tigapanah subdistrict. Stool samples were processed using a single Kato-Katz method. The potential risk factors analyzed were parent education and occupation, hand washing habits, latrine usage, footwear usage and contact with soil. The Chi-square test was performed to identify an association between risk factors and parasitological results. Logistic regression analysis was used to measure the strength of association.

Results: We enrolled 468 school children between 6 and 12 years of age. Among those children, 268 children (57.24\%) were positive for one or more STH infections. Approximately $62.39 \%$ of children played with soil/dirt every day, and only $50 \%$ regularly washed their hands after activities. Most of the children wore shoes/slippers when going outside (87.82\%) and used a latrine for defecation (85.04\%). Playing with soil/dirt have been shown to increase the risk of STH infections 7.53 times, while hand washing habits and latrine usage decreased the risk of STH infections 0.16 times each.

Conclusion: The prevalence of STH infection in school children in Suka village, Tigapanah subdistrict is still high. Playing with soil/dirt increased the risk of infection, while hand washing habits and latrine usage decreased the risk of infection. The combined strategies of improving the personal hygiene of children and biannual deworming can reduce the risk of STH infection in school children in Suka village, Tigapanah subdistrict.

Keywords: Soil-transmitted helminth, Risk factor, School children, Indonesia

\footnotetext{
* Correspondence: ayodhia_pitaloka@yahoo.com

${ }^{1}$ Department of Child Health, Medical Faculty, Universitas Sumatera Utara,

North Sumatera, Medan, Indonesia

Full list of author information is available at the end of the article
}

(c) The Author(s). 2019 Open Access This article is distributed under the terms of the Creative Commons Attribution 4.0 International License (http://creativecommons.org/licenses/by/4.0/), which permits unrestricted use, distribution, and reproduction in any medium, provided you give appropriate credit to the original author(s) and the source, provide a link to the Creative Commons license, and indicate if changes were made. The Creative Commons Public Domain Dedication waiver (http://creativecommons.org/publicdomain/zero/1.0/) applies to the data made available in this article, unless otherwise stated. 


\section{Background}

Infection with soil-transmitted helminths (STHs) is one of the most common neglected tropical diseases in the world. Infection with these parasites is related to poverty and, the highest prevalence occurs in low and middle-income countries where hygiene and sanitation are poor $[1,2]$. It is estimated that approximately 2 billion people are infected with STHs globally [3, 4]. Ascaris lumbricoides, Trichuris trichiura, and hookworm are the most common species infecting human [5, 6]. Morbidity and mortality due to STH infections are related to the number of worms in an infected person, as well as age and immunity. School children are the most vulnerable group of people affected by the disease. In 2010, it was estimated that more than 613 million school-age children were at risk of this infection worldwide [7]. Infection of these parasites in children may result in malnutrition, poor school performance, delayed physical growth and impaired cognitive function [5, 8, 9]. The World Health Organization (WHO) is targeting the control of STH in children to reduce morbidity by 2020 through a school-based deworming program [3]. The World Health Organization developed a policy for the control of STH and schistosomiasis by promoting deworming as the cornerstone of control with the aim of reducing morbidity $[10,11]$. The World Health Organization recommends annual treatment in areas where the prevalence of STH is between 20 and 50\% and biannually where the prevalence is over 50\% [10]. However, deworming has a temporary effect on transmission and cannot prevent reinfection [11, 12]. The transmission of STH is determined by multiple factors, such as behavior, environment, health system and socioeconomic status $[13,14]$. Long-term STH control and elimination will require an integrated approach by combining deworming with the improvement of water access, sanitation (improved latrines and fecal sludge management) and hygiene (hand washing habits and wearing shoes) practices [12, 15-17]. Understanding the factors that influence an endemic area is key to effective STH control [18].

In 2010, it was estimated that 5.3 billion people, including 1 billion school children, lived in stable transmission areas for STH in the world, and nearly $70 \%$ of them lived in Asia [19]. In recent decades, Southeast Asia has been recognized as having the highest prevalence of STH infection [2]. Many countries in Southeast Asia have a moist climate that provides an ideal environment for STH embryonation and survival of eggs and larvae maturation $[2,20]$. Many areas also lack adequate water resources and have poor sanitation infrastructure [2]. North Sumatera is one of the provinces in Indonesia with the highest prevalence of STH. Data reported over a decade ago, showed that the prevalence rates were between 91 and 97\% in school children [21]. Since that time, some improvements have been made in the areas of water resources availability and increased use of latrines. Unfortunately, human habits have not changed much, and mass drug administration is not regularly provided (personal communication).

The objective of this study was to determine the prevalence of STH in North Sumatera and to identify the associated risk factors among school children. This is the first study to evaluate the potential risk factors of STH infection in school children in this area. The information provided could guide local policy makers to design a more definitive control strategy for STH in this area to achieve the global goal of STH control in 2020.

\section{Methods}

\section{Description of study area}

The study was conducted in Suka village, Tigapanah subdistrict, Karo Regency, North Sumatera, Indonesia, from May to July 2018. Tigapanah is located $76 \mathrm{~km}$ from Medan, the capital city of North Sumatera. The area which covers $219,09 \mathrm{~km}^{2}$ is mountainous, with humid weather, wet soil and agriculture is the main occupation of its inhabitants. Figure 1 shows the study area.

\section{Study design and sample size}

A cross-sectional study was carried out among primary school children in Suka village, Tigapanah subdistrict. This village was selected based on a previous study conducted in 2003, which reported the prevalence of STH to be $91.3 \%$ in school children [21]. The village has two adjacent elementary schools with similar characteristics and numbers of students. The sample size calculation was performed using a single proportion formula: $\mathrm{N}=\mathrm{P}$ (1-p) $\mathrm{Z}^{2} / \mathrm{d}^{2}$, where $\mathrm{P}=$ prevalence of STH from a previous study, $Z=$ level of confidence, 1.96 and $d=5 \%$ marginal error, which gave a minimum sample size of 122 children. Finally, we sought consent from parents of all invited children who attended school during sample collection and collected stool samples the next day for examination. Sample collection until data analysis was conducted from May to July 2018. Each of the children was provided with a unique identification (ID) code to identify each individual and avoiding repetitive sampling.

\section{Data collection}

Characteristic data, such as age, sex, nutritional status, and parent occupation and education, were collected. Children were interviewed about their self-hygiene, such as hand washing before and after defecation, latrine and footwear usage and whether they enjoyed playing with soil/dirt. That information was collected using a pretested questionnaire that was prepared for the study. It was prepared in Bahasa and checked for fitness (English 


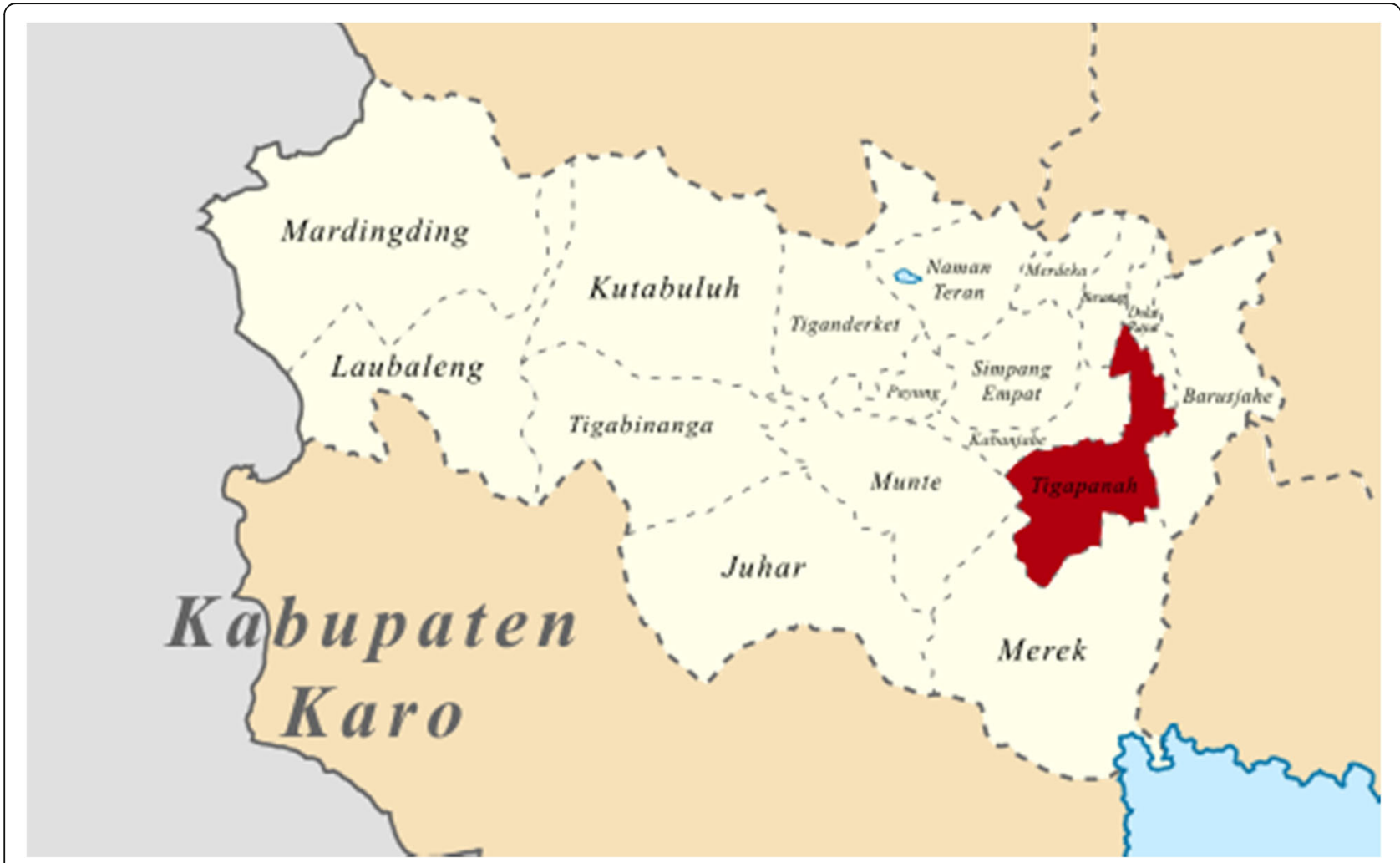

Fig. 1 Map of Tigapanah subdistrict, Karo Regency (https://commons.wikimedia.org/wiki/Category:Tigapanah,_Karo)

translated version is provided as Additional file 1). Trained study team members conducted the interview. All questionnaires were checked for completeness and accuracy.

The heights of all of the children were examined using a calibrated ruler to the nearest $0.1 \mathrm{~cm}$. Weight was measured using a calibrated scale to the nearest $0.5 \mathrm{~kg}$ without shoes. Height for age (HAZ) and weight for age (WAZ) scores were used to determine growth rate and nutritional status.

\section{Stool sample examination}

The children were provided with plastic containers that were already labeled with their unique ID and date and kept in a plastic bag. They were instructed to bring the stool sample the next morning. Diarrheic sample was withdrawn to maintain the quality of the stool samples. The samples were checked for quality and then emulsified with $10 \%$ formalin solution before being transported to Universitas Sumatera Utara in Medan for examination. Stool samples were processed using a single KatoKatz smear and microscopically examined for ova of intestinal helminths. The intensity of infection was determined as the eggs per gram (epg) of stool according to WHO guidelines [22].

\section{Data analysis}

Data were analyzed using STATA version 15.1 (Stata Corporation, College Station, Texas, USA) after checking for completeness. Descriptive data were summarized as a percentage and interquartile ranges (IQR). The potential risk factors analyzed were parent education and occupation, hand washing habits, latrine usage, footwear usage and contact with soil. Logistic regression analysis was used to explain the relationship between independent variables and STH infection. Odds ratio (OR) of the binary outcome variable was assessed by univariate analysis. All variables with $P$-value less than 0.25 were further analyzed using multivariate analysis to adjust any confounders. The final model was presented by adjusted odds ratio (AOR) with 95\% confidence interval (CI). Values were considered significant when $P<0.05$.

\section{Ethical consideration}

This study was approved by the Health Research Ethical Committee, Medical Faculty of Sumatera Utara (No. 233/TGL/KEPK FK USU-RSUP HAM/2018) and Research Ethics Committee, Universitas Padjajaran (No. 650/UN6.KEP/EC/2018). Permission to conduct the study was also approved by the Tigapanah subdistrict office, educational authorities and school principals. 
The study objective was explained to the parents, school teachers, and students before data collection. Written consent was obtained from parents before data and stool collection. Any children with positive STH infection from stool examination were treated with an appropriate dose of albendazole (chewing tablet of albendazole, $400 \mathrm{mg}$ ) provided by the Ministry of Health.

\section{Results}

\section{Characteristics of the study population}

From the descriptive analysis, we found that $51.07 \%$ of school children were boys, and the mean age of children included in this study was 9.4 (standard deviation of 4.22) years. The occupation of the majority of parents was farming both for mothers and fathers (91.67 and $79.7 \%$, respectively). Approximately $62.39 \%$ of children played with soil/dirt every day, and only $50 \%$ regularly washed their hands after activities. Most of the children wore shoes/slippers when going outside (87.82\%) and used a latrine for defecation (85.04\%). Detailed information about the characteristics of these children is provided in Table 1.

\section{Prevalence of soil-transmitted helminthiasis}

Between May and July 2018, we screened 510 school children from 2 elementary schools in Suka village, Tigapanah subdistrict. Four of the children did not participate because their parents did not provide consent, and 38 children could not be included because they did not provide stool samples. We enrolled 468 school children between 6 and 12 years of age. Among those children, 268 children (57.24\%) were positive for one or more STH infections. We also found 2 children infected with Hymenolepis nana and 1 with Enterobius vermicularis.

The most frequently identified species of STH was $A$. lumbricoides (40.17\%) (Table 2).

We found 182 children with single infection of STH (67.91\%), 83 children with double STH infections (30.97\%) and three children with triple STH infections (1.12\%).

In this study, we only detected light-intensity infections for all species of STH, based on egg per gram. For A. lumbricoides, the geometric mean epg was 984.34 (IQR: 766.31-1264.40), followed by $T$. trichiura with 108.24 epg (IQR: 91.42-128.15) and hookworms with 113.90 epg (IQR: 66.93-193.83).

\section{Potential risk factors for soil-transmitted helminth infection in school children}

The result of the logistic regression analysis is shown in Table 3. Playing with soil/dirt increased the risk of STH infection 7.53 times while each of hand washing habits and latrine usage decreased the risk by 0.16 .
Table 1 Characteristics of school children enrolled in the study

\begin{tabular}{|c|c|}
\hline Characteristics observed & School children $(N=468, \%)$ \\
\hline \multicolumn{2}{|l|}{ Sex } \\
\hline Girl & $229(48.93)$ \\
\hline Boy & $239(51.07)$ \\
\hline \multicolumn{2}{|l|}{ Age group } \\
\hline $6-10$ years old & $295(63.03)$ \\
\hline Above 10 years old & $173(36.97)$ \\
\hline \multicolumn{2}{|l|}{ Mother occupation } \\
\hline Farming & $429(91.67)$ \\
\hline Others & $39(8.33)$ \\
\hline \multicolumn{2}{|l|}{ Father occupation } \\
\hline Farming & $373(79.70)$ \\
\hline Others & $95(20.30)$ \\
\hline \multicolumn{2}{|l|}{ Mother education } \\
\hline No education & $68(14.53)$ \\
\hline Primary & $120(25.64)$ \\
\hline Secondary & $246(52.56)$ \\
\hline High school & $34(7.26)$ \\
\hline \multicolumn{2}{|l|}{ Father education } \\
\hline No education & $101(21.58)$ \\
\hline Primary & $156(33.33)$ \\
\hline Secondary & $195(41.67)$ \\
\hline High school & $16(3.42)$ \\
\hline \multicolumn{2}{|l|}{ Nutritional status } \\
\hline Average & $315(69.31)$ \\
\hline Underweight & $93(19.87)$ \\
\hline Overweight & $60(12.82)$ \\
\hline Playing with soil/dirt & $292(62.39)$ \\
\hline Wearing shoes/slippers & $411(87.82)$ \\
\hline Latrine usage & $398(85.04)$ \\
\hline Hand washing habit & $234(50)$ \\
\hline
\end{tabular}

We also analyzed the association between potential risk factors and STH species. For infection with A. lumbricoides, playing with soil/dirt increased the risk of infection 2.56 times while hand washing habits and latrine usage decreased the risk of infection by 0.38 and 0.30 times, respectively. For infection with $T$. trichiura, playing with soil/dirt increased the risk of infection by 4.44 times, while hand washing habits decreased the infection 0.31 times. We did not perform a logistic regression analysis for hookworm because the sample size was too small.

\section{Discussion}

Our study showed that soil-transmitted helminth infections are prevalent among school children in Suka village, Tigapanah subdistrict. The present finding shows 
Table 2 Prevalence and multiplicity of soil-transmitted helminth infection in school children in Suka village

\begin{tabular}{lll}
\hline Variables & Number positive $(\mathrm{N}=468)$ & Prevalence (\%) \\
\hline STH Species & & \\
Ascaris lumbricoides & 188 & 40.17 \\
Trichuris trichiura & 156 & 33.33 \\
Hookworms & 16 & 3.42 \\
Infection types & & \\
Mono-infection & 182 & 67.91 \\
Dual infection & 83 & 30.97 \\
Triple infection & 3 & 1.12 \\
Gender & 133 & \\
Female & 135 & 49.6 \\
Male & & 50.4 \\
Age group & 170 & 63.4 \\
6-10 years & 98 & 36.6 \\
$>$ 10 years &
\end{tabular}

that the prevalence of STH decreased by over $34 \%$ when compared with the report of Pasaribu [21]. This finding suggests improvement in water resources and sanitation infrastructure in the area. The finding is however higher than the reports of 7.6 and $34.4 \%$ in Northern Sumatera
[23] and Suka village [24] respectively. We enrolled more children less than ten years old in this study, which was similar to the study by Alemeshet [25].

In the present study, A. lumbricoides was the most predominant STH species, followed by $T$. trichiura (33.33\%) and then hookworms (3.42\%) This finding is similar to the report of Wang et al. [26] in China, but contrary to the reports of Alelign et al. [27] in Northwestern Ethiopia which reported predominance of hookworms. Predominance of T. trichiura over other species of STH was also reported in Ethiopia and Cote d'Ivore $[13,28]$. It was estimated that $A$. lumbricoides is attributed to the highest burden of STH infection in the world and is most commonly found in children, while hookworms are more common in adults. Approximately $87.82 \%$ of the children in our study wore shoes while playing outside, which contributed to the reduced number of hookworm infections. Interestingly, we also found some children in our study who were infected with Hymenolepis nana and Enterobius vermicularis. We did not find any infection with $S$. stercoralis, probably because of the use of Kato Katz method, which is limited in detecting the parasite [29].

In line with the report of Abossie et al. [30] from southern Ethiopia, we found mono, dual and triple infections in $67.91,30.97$ and $1.12 \%$ of children respectively.

Table 3 Factors associated with soil-transmitted helminth infection in school children in Suka village

\begin{tabular}{|c|c|c|c|c|c|c|c|}
\hline \multirow[t]{2}{*}{ Risk factors } & \multicolumn{2}{|c|}{ Total examined $\mathrm{N}=468$} & \multicolumn{2}{|c|}{ Bivariate analysis } & \multicolumn{3}{|c|}{ Multivariate analysis } \\
\hline & $\mathrm{STH}(n=268)$ & No STH $(n=200)$ & OR & $95 \% \mathrm{Cl}$ & $\mathrm{AOR}$ & $95 \% \mathrm{Cl}$ & $P$-value \\
\hline Mother occupation & & & 0.77 & $0.39-1.48$ & & & \\
\hline Farming & 248 & 181 & & & & & \\
\hline Others & 20 & 19 & & & & & \\
\hline Father occupation & & & 1.03 & $0.66-1.63$ & & & \\
\hline Farming & 213 & 160 & & & & & \\
\hline Others & 55 & 40 & & & & & \\
\hline \multicolumn{8}{|l|}{ Mother education } \\
\hline No education & 40 & 28 & & & & & \\
\hline Primary & 74 & 46 & 1.13 & $0.61-2.07$ & & & \\
\hline Secondary & 139 & 107 & 0.91 & $0.53-1.57$ & & & \\
\hline High school & 15 & 19 & 0.55 & $0.24-1.27$ & & & \\
\hline \multicolumn{8}{|l|}{ Father education } \\
\hline No education & 64 & 37 & & & & & \\
\hline Primary & 99 & 57 & 1.004 & $0.59-1.69$ & 1.11 & $0.60-2.07$ & \\
\hline Secondary & 98 & 97 & 0.58 & $0.36-0.96$ & 0.69 & $0.38-1.23$ & \\
\hline High school & 7 & 9 & 0.45 & $0.16-1.31$ & 0.61 & $0.17-2.15$ & \\
\hline Playing with soil/dirt & 126 & 166 & 1.87 & $1.61-2.17$ & 7.53 & $4.54-12.49$ & $<0.001$ \\
\hline Not wearing shoes/slippers & 47 & 10 & 4.041 & $1.99-8.21$ & 1.82 & $0.67-4.93$ & \\
\hline Latrine usage & 59 & 11 & 0.21 & $0.10-0.40$ & 0.16 & $0.07-0.35$ & $<0.001$ \\
\hline Hand washing habit & 177 & 57 & 0.21 & $0.14-0.30$ & 0.16 & $0.10-0.26$ & $<0.001$ \\
\hline
\end{tabular}


This finding is however contrary to other reports from Ethiopia [25, 30, 31]. Most of the dual infections observed were due to $A$. lumbricoides and $T$. trichiura similar to the report of Debalke et al. [28]. The global predominance of these two species and the humid weather and wet soil in Suka village may explain their abundance in the study region. The prevalence of triple infections was lower than reports from Honduras [14, 32]. Multi-parasitism were also reported in Asia [33, 34].

A study by Erismann in Burkina Faso showed moderate-intensity of STH infections [35], while in our study all infections were of light intensity. However, our result is similar to the finding of Davis et al. [36] which also showed light- intensities of STH infections. Although the number of epg was considered low, STH infection may have a negative impact on children's health and quality of life, as shown by AlMekhlafi in Yemen [37].

Our study assessed the association of potential risk factors with the prevalence of STH infection. Parents education and occupation, the habit of playing with soil/ dirt, not wearing shoes/slippers, latrine usage, and hand washing habits were the factors that we used in the analysis. We did not find any association between parent education and occupation with the risk of STH infection. A related study by Terefa [38] also showed similar result. However Wang [26], showed that mother's education level contributed to the occurrence of STH infection contrary to the present finding. Playing with soil/dirt increased the risk of STH 7.53 times, while latrine usage and hand washing habit significantly reduced the risk of STH by 0.16 times each. Studies carried out in Honduras and Malaysia also confirmed the fact that open defecation can increase the risk of polyparasitism by nearly two times $[14,39,40]$. From multivariate analysis, we did not find an association between wearing shoes/ slippers and the risk of STH infection. This finding is similar to those in the study performed by Ahmed in Malaysia [41].

When we analyzed the association between species of STH and the prevalence of infection, playing with soil/ dirt increased the risk for both A. lumbricoides 2.56 times and T. trichiura infections 4.44 times. Hand washing habits decreased the risk of both A. lumbricoides and T. trichiura infections, 0.38 and 0.31 times, respectively. Latrine usage decreased the risk of $A$. lumbricoides infection 0.30 times but had no association for T. trichiura infection.

A study conducted by Tabi et al. [42] also showed that open defecation is a risk factor for STH infections. Lack of hand washing was also reported as a risk factor for STH infection [43].

This is the first study to evaluate the risk factors of personal hygiene in school children and their associations with STH infection in Suka village. Our study findings will inform public health authorities to develop a relevant STH control strategy in Suka village, Tigapanah subdistrict.

\section{Conclusions}

The prevalence of STH infection in school children in Suka village, Tigapanah subdistrict is still high. Children's personal hygiene was associated with the prevalence of STH, but we found no association between parent's education and occupation with the prevalence of STH. Playing with soil/dirt increased the risk of infection, but hand washing habits and latrine usage potentially decreased the risk of infection. The combined strategies of improving the personal hygiene of children and biannual deworming will reduce the risk of STH infection in school children in Suka village, Tigapanah subdistrict.

\section{Additional file}

Additional file 1: English translated version of study questionnaire (Interview guide). This file is an English translated version of study questionnaire. The original version is in Bahasa Indonesia and was used in participant interview. (DOCX $19 \mathrm{~kb}$ )

\begin{abstract}
Abbreviations
A. lumbricoides: Ascaris lumbricoides; AOR: Adjusted odds ratio;

$\mathrm{Cl}$ : Confidence interval; EPG: Egg per gram; HAZ: Height for age;

ID: Identification code; IQR: Interquartile range; OR: Odds ratio; STH: Soil transmitted-helminth; T. trichiura: Trichuris trichiura; WAZ: Weight for age; WHO: World Health Organization
\end{abstract}

\section{Acknowledgements}

The authors would like to thank the parents and study participants for their participation, Suka village education office, school principals and teachers for their cooperation.

\section{Authors' contributions}

APP, AA, DS and SP conceived the idea for this study and participated in the design and conduct of the study. APP and KS were responsible for the accuracy of the data, drafted the manuscript and performed the statistical analysis. APP interpreted the findings. All authors read and approved the final manuscript.

\section{Funding}

No special funding was required for this study.

\section{Availability of data and materials}

The data sets in this study are available from the corresponding author on reasonable request.

\section{Ethics approval and consent to participate}

This study was reviewed and ethically approved by the Health Research Ethical Committee, Medical Faculty of Sumatera Utara and Research Ethics Committee, Universitas Padjajaran. Permission to conduct the study was also obtained from Tigapanah subdistrict Office, Educational Bureau, and School Principals. The objective of the study was explained to parents, school teachers and students before data collection. Data collection and stool samples were collected after obtaining written consent from parents. Individuals positive for STHs, $H$. nana and $E$. vermicularis were treated with a suitable dose of albendazole. 


\section{Consent for publication}

Not applicable.

\section{Competing interests}

The authors declare that they have no competing interests.

\section{Author details}

'Department of Child Health, Medical Faculty, Universitas Sumatera Utara, North Sumatera, Medan, Indonesia. ${ }^{2}$ Department of Child Health, Medical Faculty, Universitas Padjajaran, Bandung, West Java, Indonesia.

Received: 19 December 2018 Accepted: 30 July 2019

Published online: 07 August 2019

\section{References}

1. Brooker S. Estimating the global distribution and disease burden of intestinal nematode infections: adding up the numbers-a review. Int J Parasitol. 2010;40(10):1137-44.

2. Utzinger J, Bergquist $R$, Olveda $R$, Zhou XN. Important helminth infections in Southeast Asia diversity, potential for control and prospects for elimination. Adv Parasitol. 2010:72:1-30.

3. WHO. Eliminating Soil-Transmitted Helminthiases as a Public Health Problem in Children: Progress Report 2001-2010 and Strategic Plan 20112020. 2012.

4. Brooker S, Clements AC, Bundy DA. Global epidemiology, ecology and control of soil-transmitted helminth infections. Adv Parasitol. 2006;62:221-61.

5. de Silva NR, Brooker S, Hotez PJ, Montresor A, Engels D, Savioli L. Soiltransmitted helminth infections: updating the global picture. Trends Parasitol. 2003:19(12):547-51.

6. Jourdan PM, Lamberton PHL, Fenwick A, Addis DG. Soil-transmitted helminth infections. Lancet. 2017:391:252-65

7. WHO. Soil-transmitted helminthiases: Number of Children Treated in 2010. 2012.

8. Raj SM, Sein KT, Anuar AK, Mustaffa BE. Effect of intestinal helminthiasis on school attendance by early primary schoolchildren. Trans R Soc Trop Med Hyg. 1997;91(2):131-2.

9. Curtale F, Tilden R, Muhilal VY, Pokhrel RP, Guerra R. Intestinal helminths and risk of anaemia among Nepalese children. Panminerva Med. 1993;35(3):159-66.

10. WHO. Helminth control in school age children: a guide for managers of control programmes. 2nd ed. Geneva: World Health Organization; 2011.

11. WHO. Accelerating work to overcome the global impact of neglected tropical diseases - a roadmap for implementation. Geneva: World Health Organization; 2012.

12. Campbell SJ, Savage GB, Gray DJ, Atkinson J-AM, Soares Magalhaes RJ, Nery SV, McCarthy JS, Velleman Y, Wicken JH, Traub RJ. Water, sanitation, and hygiene (WASH): a critical component for sustainable soil-transmitted helminth and schistosomiasis control. PLoS Negl Trop Dis. 2014;8(4):e2651.

13. Coulibaly JT, Furst T, Silue KD, Knopp S, Hauri D, Ouattara M, Utzinger J, N'Goran EK. Intestinal parasitic infections in schoolchildren in different settings of cote d'Ivoire: effect of diagnostic approach and implications for control. Parasit Vectors. 2012;5:135.

14. Gabrie JA, Rueda MM, Canales M, Gyorkos TW, Sanchez AL. School hygiene and deworming are key protective factors for reduced transmission of soiltransmitted helminths among schoolchildren in Honduras. Parasit Vectors. 2014;7:354.

15. Bartram J, Cairncross S. Hygiene, sanitation, and water: forgotten foundations of health. PLoS Med. 2010;7(11):e1000367.

16. Greene LE, Freeman MC, Akoko D, Saboori S, Moe C, Rheingans R. Impact of a school-based hygiene promotion and sanitation intervention on pupil hand contamination in Western Kenya: a cluster randomized trial. Am J Trop Med Hyg. 2012;87(3):385-93.

17. Truscott JE, Hollingsworth TD, Brooker SJ, Anderson RM. Can chemotherapy alone eliminate the transmission of soil transmitted helminths? Parasit Vectors. 2014:7:266.

18. Lustigman S, Prichard RK, Gazzinelli A, Grant WN, Boatin BA, McCarthy JS, Basanez MG. A research agenda for helminth diseases of humans: the problem of helminthiases. PLoS Negl Trop Dis. 2012;6(4):e1582.

19. Pullan RL, Brooker SJ. The global limits and population at risk of soiltransmitted helminth infections in 2010. Parasit Vectors. 2012;5:81.
20. Pullan RL, Smith JL, Jasrasaria R, Brooker SJ. Global numbers of infection and disease burden of soil transmitted helminth infections in 2010. Parasit Vectors. 2014;7:37

21. Pasaribu S. Penentuan Frekuensi Optimal Pengobatan Massal Askariasis dengan Albendazole pada Anak Usia Sekolah Dasar di Desa Suka. Pendekatan Dinamika Populasi Cacing. Medan: Universitas Sumatera Utara; 2004

22. WHO. Prevention and control fo schistosomiasis and soil transmitted helminthiasis. 2002.

23. Darlan DM, Tala ZZ, Amanta C, Warli SM, Arrasyid NK. Correlation between soil transmitted helminth infection and eosinophil levels among primary school children in Medan. Open Access Maced J Med Sci. 2017:5(2):142-6.

24. Novianty S, Dimyati Y, Pasaribu S, Pasaribu AP. Risk Factors for SoilTransmitted Helminthiasis in Preschool Children Living in Farmland, North Sumatera, Indonesia. J Trop Med. 2018;2018:6706413.

25. Yami A, Yoseph M, Saleshi K. Prevalence and predictors of intestinal helminthiasis among school children in Jimma zone; a cross-sectional study. Ethiop J Health Sci. 2011;21(3):167-74.

26. Wang $X$, Zhang L, Luo R, Wang G, Chen Y, Medina A, Eggleston K, Rozelle S, Smith DS. Soil-transmitted helminth infections and correlated risk factors in preschool and school-aged children in rural Southwest China. PLoS One. 2012;7(9):e45939.

27. Alelign T, Degarege A, Erko B. Soil-Transmitted Helminth Infections and Associated Risk Factors among Schoolchildren in Durbete Town, Northwestern Ethiopia. J Parasitol Res. 2015;2015:641602.

28. Debalke S, Worku A, Jahur N, Mekonnen Z. Soil transmitted helminths and associated factors among schoolchildren in government and private primary school in Jimma Town, Southwest Ethiopia. Ethiop J Health Sci. 2013;23(3):237-44

29. Knopp S, Mgeni AF, Khamis IS, Steinmann P, Stothard JR, Rollinson D, Marti $\mathrm{H}$, Utzinger J. Diagnosis of soil-transmitted helminths in the era of preventive chemotherapy: effect of multiple stool sampling and use of different diagnostic techniques. PLoS Negl Trop Dis. 2008;2(11):e331.

30. Abossie A, Seid M. Assessment of the prevalence of intestinal parasitosis and associated risk factors among primary school children in Chencha town, Southern Ethiopia. BMC Public Health. 2014:14:166.

31. Samuel F, Demsew A, Alem Y, Hailesilassie Y. Soil transmitted Helminthiasis and associated risk factors among elementary school children in Ambo town, Western Ethiopia. BMC Public Health. 2017;17:791.

32. Sanchez AL, Gabrie JA, Usuanlele MT, Rueda MM, Canales M, Gyorkos TW. Soil-transmitted helminth infections and nutritional status in school-age children from rural communities in Honduras. PLoS Negl Trop Dis. 2013;7(8):e2378.

33. Steinmann $P$, Du ZW, Wang LB, Wang XZ, Jiang JY, Li LH, Marti H, Zhou XN, Utzinger J. Extensive multiparasitism in a village of Yunnan province, People's Republic of China, revealed by a suite of diagnostic methods. Am J Trop Med Hyg. 2008;78(5):760-9.

34. Shrestha A, Sharma S, Gerold J, Erismann S, Sagar S, Koju R, Schindler C, Odermatt P, Utzinger J, Cisse G. Water Quality, Sanitation, and Hygiene Conditions in Schools and Households in Dolakha and Ramechhap Districts, Nepal: Results from A Cross-Sectional Survey. Int J Environ Res Public Health. 2017;14(1):E89. https://doi.org/10.3390/ijerph14010089.

35. Erismann S, Diagbouga S, Odermatt $P$, Knoblauch AM, Gerold J, Shrestha A, Grissoum T, Kabore A, Schindler C, Utzinger J, Cisse G. Prevalence of intestinal parasitic infections and associated risk factors among schoolchildren in the plateau central and Centre-Ouest regions of Burkina Faso. Parasit Vectors. 2016;9(1):554.

36. Davis SM, Worrell CM, Wiegand RE, Odero KO, Suchdev PS, Ruth LJ, Lopez G, Cosmas L, Neatherlin J, Njenga SM, Montgomery JM, Fox LM. Soiltransmitted helminths in pre-school-aged and school-aged children in an urban slum: a cross-sectional study of prevalence, distribution, and associated exposures. Am J Trop Med Hyg. 2014;91(5):1002-10.

37. Al-Mekhlafi AM, Abdul-Ghani R, Al-Eryani SM, Saif-Ali R, Mahdy MA. Schoolbased prevalence of intestinal parasitic infections and associated risk factors in rural communities of Sana'a. Yemen Acta Trop. 2016;163:135-41.

38. Tefera E, Mohammed J, Mitiku H. Intestinal helminthic infections among elementary students of Babile town, eastern Ethiopia. Pan Afr Med J. 2015; 20:50.

39. Ziegelbauer K, Speich B, Mausezahl D, Bos R, Keiser J, Utzinger J. Effect of sanitation on soil-transmitted helminth infection: systematic review and meta-analysis. PLoS Med. 2012;9(1):e1001162. 
40. Ngui R, Aziz S, Chua KH, Aidil RM, Lee SC, Tan TK, Sani MM, Arine AF, Rohela M, Lim YAL. Patterns and risk factors of soil-transmitted helminthiasis among orang Asli subgroups in peninsular Malaysia. Am J Trop Med Hyg. 2015:93(2):361-70.

41. Ahmed A, Al-Mekhlafi HM, Choy SH, Ithoi I, Al-Adhroey AH, Abdulsalam AM, Surin J. The burden of moderate-to-heavy soil-transmitted helminth infections among rural malaysian aborigines: an urgent need for an integrated control programme. Parasit Vectors. 2011;4:242.

42. Tabi ESB, Eyong EM, Akum EA, Love J, Cumber SN. Soil-transmitted Helminth infection in the Tiko Health District, South West Region of Cameroon: a post-intervention survey on prevalence and intensity of infection among primary school children. Pan Afr Med J. 2018;30:74.

43. Tchakounte BN, Nkouayep VR, Pone JW. Soil contamination rate, prevalence, intensity of infection of Geohelminths and associated risk factors among residents in Bazou (West Cameroon). Ethiop J Health Sci. 2018;28(1):63-72.

\section{Publisher's Note}

Springer Nature remains neutral with regard to jurisdictional claims in published maps and institutional affiliations.

Ready to submit your research? Choose BMC and benefit from:

- fast, convenient online submission

- thorough peer review by experienced researchers in your field

- rapid publication on acceptance

- support for research data, including large and complex data types

- gold Open Access which fosters wider collaboration and increased citations

- maximum visibility for your research: over $100 \mathrm{M}$ website views per year

At BMC, research is always in progress.

Learn more biomedcentral.com/submissions 